\title{
Research on power grid operation and maintenance cost based on analysis of internal and external influence factors
}

\author{
Geli Zhang ${ }^{1 *}$, Heng Zhang ${ }^{l}$, Yan Zheng ${ }^{l}$, Yaqiong Liu ${ }^{l}$, Tong Li $^{l}$, Meibao Wang and Xiaohui Wang ${ }^{l}$
}

${ }^{1}$ State Grid Economic and Technological Research Institute Co. Ltd., Beijing, China

\begin{abstract}
In the context of the company's cost-reduction reform, lean production operation and maintenance cost management as the goal, production and maintenance cost analysis as the carrier, the existing power grid production and maintenance business and financial accounting costs to achieve "industry-finance integration" as the goal of management projects. Under the strategic background of reducing cost and increasing benefit, the implementation of this project is of great significance to optimize the main part of the cost of the company to optimize the configuration of production cost, to control reasonably, to enhance management.
\end{abstract}

\section{Introduction}

The reasonable arrangement of production cost can ensure the normal operation of equipment is the basic condition of the company's production and operation. The objective of this project is to achieve a reasonable allocation of production costs, control production costs. The production cost of the equipment is the main component of the company's operating cost. The analysis of the production cost of the equipment is of great significance, cost analysis is carried out according to the operation cost standard of power grid maintenance, pre-schedule and quota of power grid maintenance, PMS equipment account, business data and financial accounting cost data. Statistical basic data, determine analysis indicators, put forward the current management status and futureoriented lean management indicators and methods.

Guide the company operation and maintenance cost management, operation and Inspection Strategy Optimization, power grid asset management overall upgrade. In the company's system to carry out work in stages, through the main grasp of typical units in-depth mining of the analysis of production costs, the formation of a general analysis of the outline, at the same time, the relevant units based on practical experience and theory with practice, taking equipment management as the core, combining finance, radiation development, material and so on, sum up the configuration experience of production cost. Through the promotion of the headquarters, fully promote the company's advanced management experience in the company-wide units to point-to-point, in the company's production cost management-related professional, play the role of this lean management promotion model. This project is complementary to the standard cost and multi-dimensional lean management and control of finance, and is consistent with the company's strategic direction of cost reduction. Be able to check the capital management of the company's transportation and inspection costs by means of the actual completion of the cost budget analysis, cost input and output effectiveness analysis, and feed back to the formulation of the company's financial professional cost budget, make the cost budget more reasonable, through mining the cost allocation method of advanced units, management experience of continuous summary and enhance communication, for the rational use of production costs of the company has a model, enhance the role.

The direction of the project development is scientific and reasonable: through the "financial integration" management perspective, fully carry out the analysis of operation and maintenance costs, in line with the company's internal and external business situation to the production cost management requirements and expectations, it is beneficial to the scientific management of the company to carry out basic analysis by lean analysis and reduce operating cost reasonably by means of forecasting and problem mining. 2. Methods Scientific and reasonable: to establish the normal analysis mechanism of equipment transportation and inspection cost of headquarters, provincial companies and prefectural and municipal companies.

Design production cost analysis using statistical analysis, correlation analysis and other analysis ideas, design the system of cost analysis indicators and methods [1-5], based on the historical operating data analysis, multidimensional display of the use of production costs, after checking and checking the analysis data, the basic reliability of the analysis conclusion is high, which can guide the company to manage the production cost. 3 . The division of production cost is scientific: taking the operation and maintenance cost of a single station and a single line as the analysis object, fully considering the factors of self-operation and outsourcing, and reasonably calculating the cost level.

\footnotetext{
* Corresponding author: fredistheone@126.com
} 


\section{Accurate input of power grid cost}

To guide the accurate input of the operation and inspection cost into the substation-level cost object [5-10], and to rationalize the cost input and control the unreasonable cost by analyzing the reasonable allocation of the cost. By forming the final analysis report, the curing analysis outline makes it have the normal development condition, the analysis result guides the equipment selection, enhances the equipment economy under the life cycle cost angle of view, promotes the equipment own operation cost ratio. By analyzing the problems of high operation and low operation and maintenance, supporting the related decision, considering the cost factor, analyzing the reasonable time of technical renovation and overhaul, improving the overall economic benefit of power grid. The political and economic conditions in the new normal have changed profoundly, which brings great challenges to the development of power grid enterprises. General Industrial and commercial electricity price decline, transmission and distribution price regulation, economic changes at home and abroad are increasingly complex, economic downturn is expected to increase and so on.

In order to maintain the normal operation of the Power Grid Enterprise, the power grid enterprise needs to reduce the operating cost, control the cost input reasonably and reduce the cost burden. With the increasing difficulty of operation, if power grid enterprises want to continue to improve quality and efficiency, they need to raise the level of input and output, raise the level of cost management and control, and improve the profitability of enterprises by reducing costs and increasing efficiency, ensure the healthy development of power grid industry. The strengthening of the supervision of power transmission and distribution price is reflected in the reform of power system that the power transmission and distribution price should be approved according to the principle of "permitted costplus reasonable income". The transmission and distribution price of the power grid shall first verify the permitted income of the transmission and distribution business of the power grid enterprise, and then verify the transmission and distribution price on the basis of the permitted income. The permitted income of power grid is composed of permitted cost, permitted income and tax.

Therefore, in the case of a certain amount of electricity, the transmission and distribution price is directly proportional to the permitted income of the power grid company, and the verification of the income and taxes is relatively clear in the process of price verification, which can be based on the identification principle of effective assets, as well as the income rate, tax rate and other parameters accurate calculation, so the approval of the permitted cost becomes the key to straighten out the transmission and distribution price. In order to adapt to the supervision and examination of power transmission and distribution cost, the State Grid Co., Ltd., through the reform and optimization of the operation and Management Strategy Work Program, proposed to study the reasonable level of operation and maintenance cost of each province and each kind of operation and management strategy in the key work task of optimizing the operation and management strategy, to provide support basis for cost supervision policy. It is helpful to realize the standardization and standardization of operation and maintenance cost, to adapt to the supervision and examination of transmission and distribution cost, to improve the cost management level of power grid enterprises, and to push forward the reform of power system. First, the research results of the project provide a standard basis for the supervision and examination of transmission and distribution costs, effectively enhance the transparency of transmission and distribution costs, and provide effective guidance for the apportionment of operation and maintenance costs among different voltage levels, it can effectively check and reflect the cost difference between different regions and different voltage levels, and lay a foundation for the proper treatment of cross-subsidy of transmission and distribution price.

The other is to standardize the pricing standard of the company's operation and maintenance cost, to improve the standardization level of the cost management of the power grid company, to help guide the scientific and lean management and control of the enterprise's cost, and to further promote the reasonable optimization of the transmission and distribution cost. The third is to provide cost calculation standards for project management personnel, assist in guiding transportation and inspection management personnel to carry out maintenance work, improve the accuracy of capital investment, and enhance the level of project management.

\section{Factor Analysis}

In order to adapt to the company's new business situation, to meet the company's strategic cost reduction and efficiency needs [16,17], cost management lean is imperative. Combined with the current pilot analysis and research work, combing the practice, summarized the current cost lean management of specific measures and objectives are as follows.

(1) carrying out the measures to realize the budget of production cost of "standard operating cost" equipment in operation and inspection: comprehensively promoting the trial use of "standard operating cost" in the companies in all provinces of China, provincial companies began to be familiar with the "standard operating costs" of the application method and the scope of the trial. Promote the localization of "standard activity cost", supplement the local characteristic activity, calculate the standard cost level of the characteristic activity, calculate the local adjustment coefficient, optimize the application of the standard cost in the local, use in the cost budget estimation and formulation. Compare the differences between the standard activity-based cost and the actual cost to further understand whether the cost level is reasonable. Continuously improve the existing "standard operating cost" system to promote the application of standard costs. (2) collecting single-station, single-line, asset group actual cost realization measures: using the existing PMS production system equipment information and the financial management system ERP project actual cost information, the actual cost incurred by a single station, a 
single line and an asset group. Through data background export and manual processing, the actual production cost is collected to station, line level and asset group level. For the company's equipment management leading financial management departments to jointly promote the codominant cost management to provide a preliminary approach.

(3) promoting project management of Production Cost: Implementation Measures: constructing the basic system of project management of production cost, including: sorting out the typical types of local operation and maintenance cost and designing cost project prototype. Classify and build the basic production cost items, build the local production cost standard items to manage the provincial reserve production cost items. Project base of local cost items according to the dimensions of specialty, equipment and operation. Formulate the cost project management method, according to the cost project driving type, categorize the whole process of project management rights and responsibilities, requirements and depth. Establish the norm standard of typical cost item.

(4) strengthening data integration to realize industry financial integration: MEASURES TO REALIZE: strengthening effective integration of PMS work task list, overhaul work list and ERP work list, strengthening data management and filling quality control; The PMS2.0 establishes the cost project management module in the PMS, strengthens the informationization support. To make the cost information collected directly in the system complete and perfect to reflect the real situation, through the system, strengthen the linkage of cost management between equipment management and Financial Accounting Management, build an interactive bridge, promote cost management.

(5) PROMOTION OF EXPLICIT MANAGEMENT OF PRODUCTION COSTS: Implementation Measures: Establishment of a management system in an all-round way, sorting out of regulations to form an enterprise standard, standardization of the operating cost management system, based on digital means, make cost explicit management efficient, accurate, flexible, interactive. Through the guiding role of the Enterprise Standard, optimize the existing cost management system in each province, make the cost management gradually transparent and open, gain the trust of the society and the supervisor. At the grass-roots level, standardize the cost information input system, digital management, avoid manual bills, through the construction of information systems to promote cost management.

(6) strengthening the measures to realize the precise input of production cost: based on the individual factors such as equipment status, age structure, terrain conditions and regional conditions, a differentiated cost input model of many influencing factors is established and constructed, assist the decision-making of capital investment of provincial company. This paper constructs the differential input model of maintenance cost, studies the Adjustment Coefficient of the differential influence factors, calculates the differential maintenance cost of different substations and overhead transmission lines, and implements the differential precise input of maintenance cost, guide the rolling correction of standard operating cost.
(7) measures to optimize the life cycle management of assets: In the stage of Type Selection and procurement, the quality of source equipment is investigated, the technical standards of equipment selection and procurement are improved, the quality of network equipment is improved, and initial investment is increased, pay attention to the life cycle cost of the equipment in the running period, form the effective assets and reduce the later maintenance cost. In the operation and maintenance stage, we should study and improve the strategy of assets operation and maintenance, raise the technical standard, strictly implement the strategy of maintenance and repair, carry out the work of standardized maintenance, improve the efficiency of operation and maintenance, strengthen the management and control of the whole process of onsite operation, and ensure the quality and safety of operation, promote the performance of maintenance operation.

\section{$4 \mathrm{LCC}$ research}

One is to continue to promote the "each device" value lean management research results. Each unit, in combination with its own business management practice, selects three kinds of operation and maintenance workers' single link connecting modes, namely "Hubei", "Jiangsu" and "Hebei (Beijing) ", to link up with the PMS system's single link, carry out a single equipment initial investment cost, operation and maintenance cost, decommissioning and disposal cost collection (or allocation), to achieve the operation and maintenance cost to each equipment accurate collection. Second, develop analysis scenario application based on LCC. Such as supplier analysis and evaluation and technical renovation decision-making. In the aspect of supplier evaluation, the average level of key equipment operation and maintenance cost is analyzed through the data collection of LCC cost, and the supplier evaluation is carried out with the indexes of equipment defect frequency, Operation State, availability coefficient, etc., to provide decision-making basis for the optimization of the company's purchasing strategy. On the basis of establishing LCC model of single equipment, calculate the operation and maintenance cost of different voltage levels, different regions, different models, different suppliers and other equipment for each year of operation and maintenance (distinguish operation and maintenance, daily maintenance, overhaul and rush repair costs), according to the results of calculation, the cost curve of operation, maintenance and repair of the main equipment is drawn, including annual input and cumulative input. The annual average operation and maintenance cost input of the equipment after technical renovation or overhaul is estimated by integrating the actual cost, and the optimal cost input is taken as the objective to assist the decisionmaking of technical renovation.

\section{Information support situation}

ERP system is still the main platform for the cost management of the operation and maintenance project, with the application unit accounting for $88.89 \%, 40.74 \%$ of the units realize the project construction through the 
Integrated Planning and Management Platform; A, B for materials and outsourcing services overall Erp service order collection, internal labor cost (Man-hour) collection carrier is not unified standards and norms; $85.19 \%$ of the implementation process data are managed by the traditional paper-based Archive (including electronic version and scanning part), and the application of physical ID can cover all specialties and assist the project implementation process management The PMS2.0 system has not been fully differentiated, only $29.63 \%$ of the units have been differentiated; the production cost management system has different functions, the overall coverage function is not comprehensive, and the data interaction with the financial budget management system is insufficient, the correlation granularity and the correlation maintenance object are insufficient.

At present, companies in all provinces have adopted the Information System to manage the operation, maintenance and repair items, the cost management of operation and maintenance project mostly adopts PMS2.0(9 units), ERP (24 units), financial budget management system (12 units), integrated planning management platform (11 units) and other production cost management system (4 units), most of the provincial companies use multiple systems for operation and maintenance project management.

The companies of all provinces have more than 2.0 integration with ERP system, less integration with financial budget management system, integrated planning management platform and production cost management system, production cost management system and financial budget management system, the development of Integrated Planning Management Platform is rarely integrated; The data interface, Web Service and big data are the main integration methods among the systems, the PM work order, material/Service purchase order and maintenance object are the data source of ERP system In the production cost information, the project basic information, the work task list, the overhaul work list, the overhaul object mainly take PMS system data as the source data, most of the provincial companies do not take the production cost management system data as the source data.

\section{Conclusion}

Aiming at the management of lean production operation and maintenance cost and relying on the analysis of production operation and maintenance cost, we can realize the reasonable allocation of production cost, control production cost, and realize the "industry-finance integration" of power network operation and maintenance cost and financial accounting cost. It is an innovative practice of cost management of municipal company to carry out the analysis of equipment production cost. Innovative production cost analysis of statistical analysis, correlation analysis, special cost analysis, special analysis is the analysis of different professional, voltage levels and other dimensions, to grasp the relationship between operation and maintenance cost including assets, safety, benefit, maintenance efficiency and so on, so as to excavate the investment effect of production cost.
Ensuring input into grid operation, maintenance and repair costs. First, it is suggested that provincial-level companies should take practical measures to guarantee the cost of maintenance and repair of power grid equipment, keep an appropriate match with the growth trend of their own power grid equipment scale, and strengthen the management of power transmission and distribution costs, scientific and rational allocation of professional cost quotas, reverse the situation of low or decreasing input level year by year, effectively ensure the safety of power grids and better serve users; second, provincial-level companies should actively integrate with the existing transmission and distribution tariff reform policies, focusing on the fact that the proportion of the newly added maintenance costs to the original value of the newly added assets is gradually approaching $2.5 \%$, with the goal of power grid security and the company's longterm development as its goal, to ensure the input of its own unit's maintenance costs, for the next transmission and distribution nuclear price cycle to lay a good foundation.

Improving Midwestern Sectional Figure Skating Championships operation and maintenance standards. First, the mechanism of coordinated development should be studied. The Midwestern Sectional Figure Skating Championships economy is relatively backward, and the profit level is generally low, so it is suggested that the company should study and try to put in place the compensation and pricing mechanism for power supply services in remote areas at the national level, so as to improve the profitability of the companies in the relevant provinces. Strive for "east-west help" and other internal cooperative development mechanism to ensure that it has the necessary operation and maintenance cost input capacity. Second, optimize the assessment system. Comprehensive optimization, overall coordination and adjustment of the company's profit, debt ratio, cost input and other evaluation and assessment system, combined with the research results of transmission and distribution price verification, to find a reasonable balance point and guide the maintenance cost of power grid operation to maintain a reasonable level, to ensure the company's longterm healthy and stable development.

Third, we should face up to the differences between the East and the West. The differential operation and maintenance standards are adopted to reasonably reduce the demand for high power supply reliability in the western region, and to improve the operation and maintenance quality and reduce the pressure on the operation and maintenance cost in the less developed areas by paying close attention to the basic, basic and basic skills. The cost of operation, maintenance and repair is the necessary guarantee for the safety production of power grid. Through this investigation, it is found that there is indeed a gap in the operation and maintenance cost of some units, which needs to be solved through measures such as studying policy, perfecting mechanism, carrying out differential operation and maintenance, and optimizing management mode, so as to ensure the safe and stable operation of the power grid, for the company to win a comprehensive "one strong three excellent" modern company, accelerate the building of a world-class 
enterprises with global competitiveness to lay a solid foundation.

\section{Acknowledgments}

The fund support comes from: The research of reasonable configuration of operation and maintenance cost difference based on equipment status (ZZKJ-2021-10)

\section{References}

1. Niknam T, Azizipanah-Abarghooee R, Narimani M R. An efficient scenario-based stochastic programming framework for multi-objective optimal micro-grid operation[J]. Applied Energy, 2012, 99:455-470.

2. Mohamed A, Radwan A A. Hierarchical Control System for Robust Microgrid Operation and Seamless Mode Transfer in Active Distribution Systems[J]. IEEE Transactions on Smart Grid, 2011, 2(2):352-362.

3. Zeineldin H H, El-Saadany E F, Salama M. Distributed Generation Micro-Grid Operation: Control and Protection[C]// Power Systems Conference: Advanced Metering. IEEE, 2006.

4. Al-Saedi W, Lachowicz S W, D Habibi, et al. Power quality enhancement in autonomous microgrid operation using Particle Swarm Optimization[J]. International Journal of Electrical Power \& Energy Systems, 2012, 42(1):139-149.

5. Rui G E, Dong Y, Yue-Chun L. Analysis of LargeScale Blackout in UCTE Power Grid and Lessons to be Drawn to Power Grid Operation in China[J]. power system technology, 2007, 31(3):1-6.

6. Kim H M, Lim Y, Kinoshita T. An Intelligent Multiagent System for Autonomous Microgrid Operation[J]. Energies, 2012, 5(12).

7. Kim H M, Kinoshita T. A Multiagent System for Microgrid Operation in the Grid-interconnected Mode[J]. Journal of Electrical Engineering and Technology, 2010, 5(2):246-254.

8. Kim, HakMan, Lim, et al. Energies, Vol. 5, Pages 3347-3362: An Intelligent Multiagent System for Autonomous Microgrid Operation[J]. 2012.

9. Pei W, Li S, Li H, et al. Key technology and testbed for microgrid operation control[J]. Automation of Electric Power Systems, 2010, 34(1):94-96.

10. Daryoush, Habibi, Octavian, et al. Power flow control in grid-connected microgrid operation using Particle Swarm Optimization under variable load conditions $[\mathrm{J}]$. International journal of electrical power and energy systems, 2013.

11. Tang X, Deng W, Li N, et al. Control technologies of micro-grid operation based on energy storage[J]. Electric Power Automation Equipment, 2012, 32(3):99-103+108.

12. Gupta, R. A, Kishor N. A robust optimization based approach for microgrid operation in deregulated environment. [J]. Energy Conversion \& Management, 2015.

13. Kim H M, Kinoshita T, Lim Y, et al. A Bankruptcy Problem Approach to Load-shedding in Multiagentbased Microgrid Operation[J]. Sensors, 2010, 10(10):8888-8898.

14. Sachs J, Sawodny O. A Two-Stage Model Predictive Control Strategy for Economic Diesel-PV-Battery Island Microgrid Operation in Rural Areas[J]. IEEE Transactions on Sustainable Energy, 2016, 7(3):1-11.

15. Zhang C, Chen M Y, Wang Z C. Study on control scheme for smooth transition of micro-grid operation modes[J]. Dianli Xitong Baohu yu Kongzhi/Power System Protection and Control, 2011, 39(20):1-5+10.

16. Kim, HakMan, Kinoshita, et al. Sensors, Vol. 10, Pages 8888-8898: A Bankruptcy Problem Approach to Load-shedding in Multiagent-based Microgrid Operation. 2010.

17. Huang Z, Ning Z, Tuffner F K, et al. MANGO Modal Analysis for Grid Operation: A Method for Damping Improvement through Operating Point Adjustment[J]. power transmission \& distribution, 2010 . 